\title{
O DEFICIENTE VISUAL E A ESCOLA: UM ESTUDO ETNOGRÁFICO SOB A PERSPECTIVA DA PESQUISA TRANSFORMATIVA DO CONSUMIDOR
}

\author{
The visually impaired and the school: an ethnographic study \\ based on transformative consumer research
}

\author{
Pedro Felipe da Costa Coelho* \\ Nelsio Rodrigues de Abreu*
}

\section{RESUMO}

A finalidade desta pesquisa foi analisar o consumo de serviços educacionais durante o ensino fundamental por deficientes visuais. Baseada na Pesquisa Transformativa do Consumidor, a investigação etnográfica foi desenvolvida numa ONG que atua na educação de alunos com deficiência visual. Os dados foram coletados por meio de 16 entrevistas narrativas com alunos do ensino fundamental, seis entrevistas em profundidade com gestores e professores da ONG Lar e cinco com responsáveis desses alunos, além de sete meses de observações participantes. Os resultados apontam que os colegas da escola, os professores, os gestores escolares e as ONGs que atuam com deficientes visuais são atores que interferem diretamente no comportamento de consumo dos sujeitos de pesquisa, sendo capazes de contribuir ou inibir o bem-estar subjetivo dos alunos. Além disso, a impotência diante da cobrança de taxas abusivas e a ausência de materiais didáticos adequados são características do contexto investigado que acentuam o estado de vulnerabilidade.

Palavras-chave: Pesquisa Transformativa do Consumidor. Vulnerabilidade do Consumidor. Ensino Fundamental. Deficiência visual.

\section{ABSTRACT}

The purpose of this piece of research was to analyze the consumption of educational services during elementary education by visually impaired people. Based on Transformative Consumer Research, the ethnographic research was developed in a NGO which is engaged in the education of students with visual impairment. The data were collected via 16 narrative interviews with elementary school students, six in-depth interviews with managers and teachers of the Lar NGO, five interviews with relatives of these students, and seven months of participant observation. The results indicate that the schoolmates, teachers, school managers and NGOs that work with visually impaired people interfere directly in the consumption behavior of the subjects, being able to contribute or inhibit the subjective well-being of the students. In addition, the powerlessness before unfair taxes and the lack of adequate teaching materials are characteristics of the investigated context that accentuate the vulnerability state.

Keywords: Transformative Consumer Research. Consumer Vulnerability. Elementary School. Visual Impairment.

\footnotetext{
* Professor Assistente da Universidade Federal do Oeste da Bahia. Doutorando em Administração e Controladoria na Universidade Federal do Ceará (PPAC/UFC). Membro do Grupo/CNPq: Consumo e Cibercultura - GPCiber. E-mail: pedrofelipecc@gmail.com.

** Professor do Programa de Pós-graduação em Administração da Universidade Federal da Paraíba (PPGA/ UFPB). Doutor em Administração pela Universidade Federal de Lavras (Ufla). Líder do Grupo/CNPq: Consumo e Cibercultura - GPCiber. E-mail: nelsio@gmail.com.
} 


\section{INTRODUÇÃO}

A atividade de marketing não se limita à geração de satisfação ou lealdade de clientes, mas objetiva a facilitação das trocas em organizações empresariais, sociais e públicas (KOTLER; LEVY, 1969). Embora se discuta desde a década de 1970 que este é o objetivo da disciplina, os estudos da área geralmente desconsideram o bem-estar individual e coletivo (PENIAMINA et al., 2014; TADAJEWSK; HAMILTON, 2014; RAPP; HILL, 2015; DAVIS; OZANNE; HILL, 2016). Seguindo essa tendência, a maior parte da produção científica em comportamento do consumidor, disciplina que historicamente recebe maior atenção dos acadêmicos de marketing, ignorou temáticas essenciais, como o materialismo, a sustentabilidade ambiental e a qualidade de vida dos consumidores (MICK et al., 2012).

Entretanto, a crise econômica mundial, o aumento excessivo do consumo de alimentos não saudáveis e da desigualdade social no mundo e o crescimento do consumo de tabaco foram alguns dos eventos que marcaram o século XXI e impulsionaram a criação de um movimento de pesquisadores de consumo voltado para o bem-estar das pessoas (ACR, 2017). Diante desse cenário que a Pesquisa Transformativa do Consumidor - originalmente, Transformative Consumer Research (TCR) - surgiu em 2005. Trata-se de um movimento iniciado por pesquisadores da Association for Consumer Research (ACR) que objetiva compreender os efeitos do consumo no bem-estar das pessoas, de forma a impulsionar ou resultar em ações socialmente relevantes (MICK et al., 2012).

0 interesse em estudar o consumo sob a perspectiva da TCR está aumentando internacionalmente (PETKUS, 2010; WILLIAMS; HENDERSON, 2012; DAVIS; PECHMANN, 2013; HAMILTON, 2014) e no Brasil, como se observa com a elaboração de recentes pesquisas em marketing que utilizaram a abordagem e trataram do comportamento de consumo de Pessoas com Deficiência (FARIA et al., 2012; FARIA, 2015) e de diretrizes para pesquisadores brasileiros sobre a TCR (COELHO, 2015; PINTO et al., 2016).

Além dessas pesquisas, outros tópicos são de interesse dos estudos transformativos, como o consumo de tabaco, álcool e drogas, jogos de azar, nutrição e obesidade, violência em filmes e jogos de computador e a doações de órgãos (MICK, 2006). Nota-se que tais estudos passam a considerar problemas sociais que raramente eram atentados pelos pesquisadores de marketing, além de incorporar nas investigações públicos-alvo que comumente são ignorados pelos acadêmicos, como negros, homossexuais, pessoas com deficiência, idosos e analfabetos. Os grupos de consumidores mencionados são denominados de consumidores vulneráveis (BAKER et al., 2005) em função de fatores individuais, familiares, comunitárias e macroambientais (BAKER; MASON, 2012).

Nesse sentido, as Pessoas com Deficiência (PcD) podem ser consideradas vulneráveis enquanto consumidores não somente devido às próprias características que apresentam, mas em função do contexto em que a deficiência se configura (BARNES; MERCER, 2003; BAKER, 2006), uma vez que a vulnerabilidade não é um traço inerente de um indivíduo, mas resultado da interação entre o indivíduo e seu contexto ambiental (SHULTZ II; HOLBROOK, 2009).

Dentre os quatro tipos de deficiência (auditiva, intelectual, motora e visual), a última será objeto de estudo desta pesquisa. Embora se saiba que 40,2\% das pessoas 
com deficiência no Brasil possuam carteira assinada e que cerca de $17 \%$ da população brasileira seja deficiente visual (IBGE, 2010), há pouco interesse dos pesquisadores em Administração de estudar esse grupo de consumidores (FARIA et al., 2014), apesar de iniciativas nacionais recentes demonstrarem as dificuldades enfrentadas pelos deficientes visuais enquanto consumidores (FARIA; SILVA; FERREIRA, 2012; FARIA; MOTTA, 2012; PINTO; FREITAS, 2013; COELHO; ABREU, 2015). Contudo, suas dificuldades também são evidenciadas quando os deficientes visuais procuram obter serviços básicos, como o ensino (LEITE; SILVA, 2006; DÍAZ et al., 2009).

Apesar de instrumentos legais terem sido desenvolvidos para facilitar o acesso deste grupo de consumidores ao ensino, somente a legislação não é suficiente para que a inclusão dos alunos com deficiência visual seja de fato uma realidade. A melhoria dos serviços educacionais direcionados aos alunos deficientes visuais nas instituições de ensino não está relacionada apenas com as atividades desenvolvidas em sala de aula, mas, sobretudo, com a capacitação dos profissionais que lidam com os alunos e com ajustes na estrutura física das escolas (DALL'ACQUA, 2002). Tais melhorias, portanto, relacionam-se à prestação de serviço das instituições de ensino e podem ser exploradas por pesquisadores de marketing.

Contudo, as pesquisas nacionais direcionadas à prestação de serviços educacionais em marketing tiveram foco mais detido em universidades (VELUDO-DE-OLIVEIRA; IKEDA, $2006 ;$ 2007). Muito embora se saiba que durante os nove anos de ensino fundamental o aluno deficiente visual está se adaptando ao convívio dos ditos "normais" e formando um autoconceito que irá repercutir em toda sua vida, estudos voltados para tais sujeitos de pesquisa são mais recorrentes na área de Educação (MANTOAN, 2003; COUTINHO, 2011).

Diante do fortalecimento da TCR internacional e nacionalmente; da representatividade de deficientes visuais na sociedade brasileira; da carência de estudos sobre vulnerabilidade e pessoas com deficiência; e do predomínio de estudos relativos aos serviços educacionais na área da Educação, este estudo teve por objetivo analisar o consumo de serviços educacionais durante o ensino fundamental por deficientes visuais.

Baseado nos fundamentos da TCR, os seguintes objetivos específicos foram traçados: (1) investigar as práticas de consumo dos consumidores com deficiência visual ao usufruírem de serviços educacionais durante o ensino fundamental; (2) verificar o papel de familiares, da comunidade escolar e das ONG em relação ao comportamento de consumo de deficientes visuais ao usufruírem de serviços educacionais durante o ensino fundamental; (3) identificar as pressões e os estados de vulnerabilidade de consumo vivenciados pelos deficientes visuais ao usufruírem de serviços educacionais durante o ensino fundamental; (4) compreender a percepção dos alunos sobre o consumo de serviços educacionais durante o ensino fundamental.

O tópico seguinte aborda a TCR e a vulnerabilidade do consumidor. 0 objetivo, os pressupostos e os tópicos de interesse da pesquisa transformativa do consumidor foram retratados, pois esta pesquisa foi desenvolvida seguindo os fundamentos da abordagem. $\mathrm{A}$ vulnerabilidade do consumidor, por sua vez, foi abordada por ser a lente teórica escolhida para o desenvolvimento da pesquisa. 


\section{A TCR E O CONSUMIDOR VULNERÁVEL}

A TCR é um movimento que visa incentivar, apoiar e divulgar pesquisas que primam pelos benefícios, bem-estar e qualidade de vida dos seres humanos afetados pelo consumo no mundo (ACR, 2017), através do estudo de problemas significativos para os consumidores e que possam gerar resultados para o seu benefício (PETKUS, 2010) e para sociedade como um todo. Este movimento lança um novo olhar sobre o consumo, uma perspectiva distinta da convencional, e não antagônica.

Estudos desenvolvidos à luz da abordagem prezam pela produção de conhecimento prático e capaz de melhorar a realidade dos objetos de estudos, por meio da aproximação dos pesquisadores com agentes de mudança social. Além disso, as pesquisas também devem possuir contribuições teóricas e resultados socialmente relevantes, difundidos através de estratégias de comunicação alternativas (MICK et al. , 2012), e um processo de pesquisa específico, que apresenta especificidades desde a definição do objetivo do estudo até a divulgação dos resultados (CROCKETT et al., 2013).

A TCR, entretanto, não pode ser considerada um movimento que desconsidera e critica a realização de estudos inseridos no mainstream das pesquisas em comportamento do consumidor, nem uma abordagem que objetiva substituir o foco gerencial nas pesquisas sobre o consumo. A pesquisa transformativa do consumidor lança um novo olhar sobre o consumo, uma perspectiva distinta da convencional, e não antagônica (COELHO, 2015).

Dentre os assuntos de interesse dos estudos transformativos, destaca-se o estudo da vulnerabilidade de consumidores (ACR, 2017). Em se tratando da última temática, trata-se de um fenômeno de natureza multidimensional que ocorre quando uma pessoa é impotente e torna-se dependente em uma situação de consumo que tem implicações negativas sobre a sua própria identidade (BAKER et al., 2005).

A partir das discussões acadêmicas sobre a vulnerabilidade do consumidor nas demais áreas, como no Direito (BENJAMIN et al., 2007; PINTO, 2007; CLOUGH, 2014), pesquisadores de marketing começaram a explorar esse fenômeno visando categorizar os consumidores vulneráveis (MORGAN et al., 1995; BRENKERT, 1998), distinguir vulnerabilidade real e vulnerabilidade percebida de consumo (BAKER et al., 2005), bem como retratar como o fenômeno se manifestou em diferentes contextos de consumo (BAKER, 2006; KAUFMAN-SCARBOROUGH; CHILDERS, 2009; ADKINS; JAE, 2010).

A partir dos estudos mencionados, foi desenvolvido um modelo conceitual que retrata o processo de vulnerabilidade à luz da TCR (BAKER; MASON, 2012). Trata-se do modelo da vulnerabilidade e resiliência do consumidor, que adota uma perspectiva sistêmica para abordar o fenômeno (Figura 1).

A Figura 1 apresenta a teoria da vulnerabilidade e resiliência do consumidor e os cinco elementos que o compõem: os fatores de risco (pressões), os eventos disparadores, o estado de vulnerabilidade, o pós-choque e os stakeholders do estado de vulnerabilidade e resiliência dos consumidores. 
Figura 1 - Modelo conceitual da teoria da vulnerabilidade e resiliência do consumidor

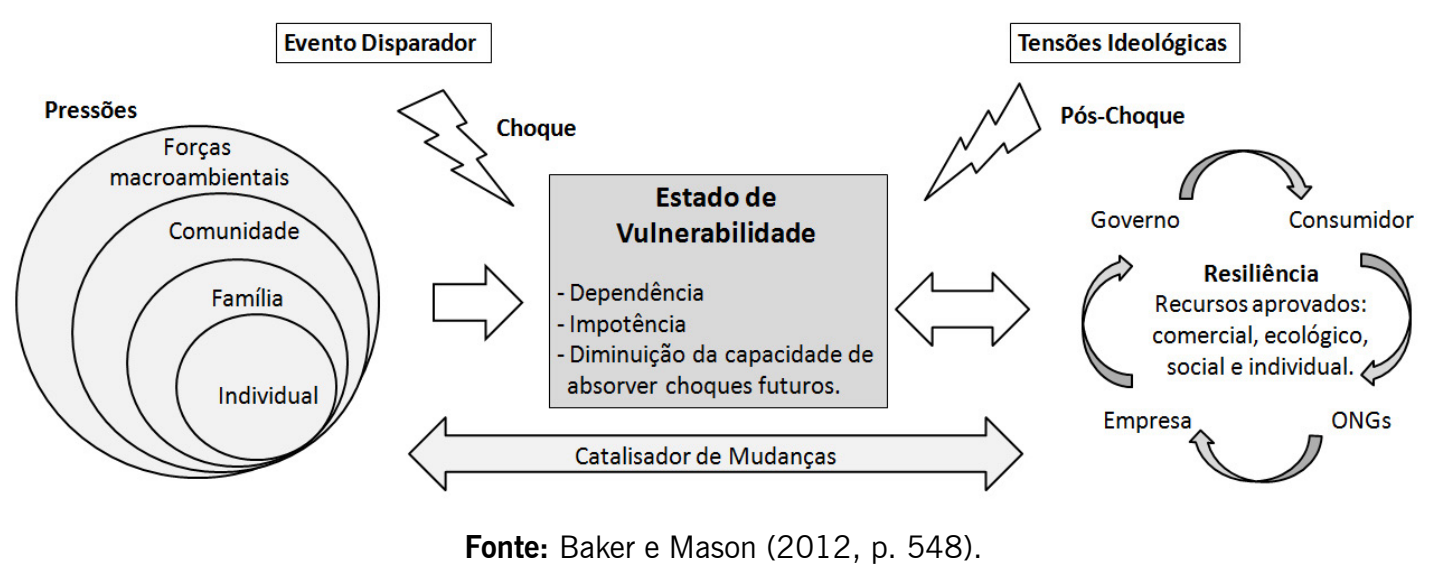

As pressões são os possíveis fatores que impulsionam a ocorrência de experiências de vulnerabilidade, ou seja, as forças macroambientais, a comunidade, a família e as características do próprio indivíduo determinam as experiências de vulnerabilidade. Essas experiências, contudo, não ocorrem somente devido às pressões, uma vez que os consumidores geralmente não vivenciam a impotência e a dependência associadas à vulnerabilidade até que um evento disparador ocorra e crie um choque que oprima sua capacidade de absorver o incidente. Os choques dos eventos disparadores podem estar vinculados a crises pessoais, como a perda de emprego ou divórcio, ou a fatores externos, como um terremoto (BAKER; MASON, 2012).

Após o choque dos eventos disparadores, o estado de vulnerabilidade de consumo é vivenciado, sendo caracterizado pela impotência e a perda de controle do indivíduo/ sociedade diante de condições externas (BAKER et al. , 2005). Após a experiência de vulnerabilidade, ocorre o pós-choque, ou seja, ações provocadas por distintos stakeholders que contribuem para a manutenção da vulnerabilidade de consumo. Os principais stakeholders são as empresas, os consumidores, o Governo e as ONGs. Tratam-se de agentes que, além de impulsionar a manutenção do estado de vulnerabilidade, também podem agir no sentido contrário e serem catalisadores de mudanças (BAKER; MASON, 2012), como a Figura 1 evidencia. Ademais, ressalta-se que, devido às pressões individuais, familiares, comunitárias e/ou macroambientais que sofrem, alguns grupos de consumidores são mais propensos a passarem por experiências de vulnerabilidade diante de práticas do mercado (BAKER; MASON, 2012).

Assim como os idosos (BARNARD, 2015), as pessoas com deficiência também são vulneráveis enquanto consumidoras, não somente devido às limitações físicas que apresentam, mas em função de uma série de fatores culturais, sociais e estruturais (KAUFMAN-SCARBOROUGH; CHILDERS, 2009). Este estudo trata das práticas de consumo de um grupo específico de pessoas com deficiência - os deficientes visuais - em um serviço básico e essencial para a sua formação - a escola de ensino fundamental. Nesse sentido, 0 tópico seguinte irá tratar do consumo de serviços educacionais pelo deficiente visual. 


\section{O CONSUMO DE SERVIÇOS EDUCACIONAIS PELO DEFICIENTE VISUAL}

Consumidores com deficiência visual enfrentam diversas dificuldades em sua rotina, incluindo obstáculos físicos em calçadas, escadas e barreiras impostas pela limitação física. Além desses aspectos, o despreparo dos prestadores de serviço público e privado para atender esse grupo de consumidores é outro fator que impede a atuação plena desses cidadãos nos ambientes de consumo (FARIAS; SILVA; FERREIRA, 2012). Tais práticas exclusivas e preconceituosas do mercado foram relatados em bancos, restaurantes, hospitais e padarias (BAKER et al., 2001; YU et al., 2015) e em compras online (CHILDERS; KAUFMAN-SCARBOROUGH, 2009; KAUFMAN-SCARBOROUGH; CHILDERS, 2009).

Fatores externos, como a acessibilidade em hotéis, ônibus de excursões e locais de passeios, são elementos que se tornam barreiras arquitetônicas e frequentemente dificultam o desfrute de experiências de consumo positivas (FARIA; MOTTA, 2012), assim como a falta de adaptações no layout e checkout das lojas (BAKER et al., 2001) e a estigmatização nos ambientes de consumo. O último aspecto foi evidenciado em Faria, Silva e Ferreira (2012), que retrataram essa realidade ao denunciarem que alguns deficientes visuais deixam de frequentar restaurantes devido ao preconceito dos atendentes e dos próprios consumidores, que comentam sobre o modo como eles fazem suas refeições.

Contudo, é importante salientar que os próprios consumidores deficientes visuais são resilientes e encontram alternativas para adaptarem-se a essas práticas do mercado, através da utilização de fontes alternativas de informação (buscando na memória, escutando comerciais, amigos e familiares) para ajudá-los no processo de decisão (AMARO et al., 2008; COELHO; ORSINI; ABREU, 2016), bem como os demais elementos sensoriais são desenvolvidos para compensar a limitação visual (PINTO; FREITAS, 2013).

Especificamente sobre o consumo de serviços educacionais, as primeiras medidas adotadas relacionadas ao ensino para a deficientes visuais no Brasil tiveram um caráter de exclusão e ocorreram por meio da criação de escolas especiais que se destinavam unicamente à educação de pessoas com deficiência (SANTOS; VIEIRA, 2006; GORNI, 2007). Com a evolução das pesquisas sobre saúde e educação, verificou-se que, dependendo das perspectivas de habilitação e reabilitação, esses alunos poderiam estudar em escolas regulares, desde que fossem oferecidos a elas instrumentos e equipamentos adequados de apoio (FERNANDES, 2006; LEITE, 2013).

Dessa forma, as instituições de educação regulares cada vez mais recebem deficientes visuais, sendo responsáveis por incluí-los neste novo espaço social e adaptando-os ao convívio dos ditos normais e vice-versa. Este convívio irá proporcionar, por meio da interação deficiente visual/dito normal, a formação de um autoconceito sobre si (positivo ou negativo) (MANTOAN, 2003; RAMOS, 2007).

Durante o ensino fundamental, esse grupo de consumo depende do engajamento de gestores públicos e privados para a sua inclusão nos ambientes de aprendizado, uma vez que existe a necessidade de capacitação no atendimento e preparo para o desenvolvimento de recursos pedagógicos e metodologias educacionais específicas voltadas para esse público, além de um esforço conjunto da família e das ONGs (BRASIL, 2000; SMEHA; SEMINOTTO, 2008; COUTINHO, 2011). 
A limitação imposta pela cegueira ou baixa visão justifica ainda a incorporação de materiais específicos no processo educativo, como o Sistema Braille e o uso do soroban, instrumento utilizado para realizar cálculos matemáticos (PASCHOAL et al., 2014). 0 professor exerce um papel fundamental nesse processo de aprendizado, visto que precisa estar atento à singularidade de cada integrante do grupo, promovendo o intercâmbio entre a diversidade de singularidades e complementando-as (MANTOAN, 2002), além de adaptar as atividades para os alunos com cegueira, utilizando materiais de diversas texturas para que o aluno possa identificar cada elemento da atividade (OLIVEIRA, 2007).

Além das necessárias adaptações, que raramente são observadas nas instituições de ensino voltadas para o ensino fundamental, outras dificuldades são enfrentadas por esse grupo de alunos (COUTINHO, 2011). O acesso ao livro, que é relativamente fácil para as pessoas videntes, torna-se difícil para os deficientes visuais, pois estes ficam dependentes de instituições que disponibilizam livros em Braile para leitura ou da boa vontade de pessoas que leiam para eles (PINHEIRO et al., 2008).

Além disso, é notório que o apelo visual tem sido privilegiado cada vez mais nas escolas, em meio a uma sociedade que é permeada por múltiplas expressões, tanto cultural quanto artísticas, onde os símbolos gráficos, imagens, letras e números fazem parte do dia-a-dia (PASCHOAL et al., 2014). No ambiente escolar, os conteúdos são abordados com base nos recursos visuais, os quais dificultam na aprendizagem dos estudantes com deficiência visual, de modo a negligenciar ao mesmo o acesso ao conhecimento (LEITE, 2013; PASCHOAL et al., 2014).

Depois de tratar do referencial teórico da pesquisa, composto pelas discussões sobre a TCR, a vulnerabilidade do consumidor e o consumo de serviços educacionais pelo deficiente visual, o tópico seguinte irá detalhar os procedimentos metodológicos adotados nesta investigação.

\section{PROCEDIMENTOS METODOLÓGICOS}

A fim de alcançar o objetivo deste estudo, conduzimos a investigação em consonância com o paradigma interpretativista e utilizando o método etnográfico (MAGNANI, 2009). Optamos pela etnografia crítica, uma vez se buscou contribuir para o desenvolvimento de políticas públicas através de conversações recíprocas com as pessoas da comunidade e os sujeitos de pesquisa, que deixam de ser "objetos de conhecimento" e se tornam colaboradores ativos no esforço de pesquisa (ANGROSINO, 2009).

A adoção da etnografia crítica é consonante com o entendimento de Crockett et al. (2013) sobre a realização de estudos transformativos sobre o consumo, uma vez que o etnógrafo crítico "não deve medir esforços para envolver toda a comunidade como parceiros ativos no desenho e na implementação da pesquisa" (ANGROSINO, 2009, p. 28) e com o ponto de vista de Faria et al. (2014, p. 34), que ressaltam a importância dos acadêmicos em administração "buscarem maneiras de fomentar a colaboração dos sujeitos deficientes com os pesquisadores".

O campo da pesquisa foi uma ONG localizada em João Pessoa-PB que oferece serviços educacionais para a criança deficiente visual, como orientação e transcrição para 
- Braille e reforço escolar na leitura e escrita comum e em Braille. Devido à solicitação dos gestores da instituição, o nome da ONG não será utilizado e aqui a denominaremos de "ONG Lar".

A ONG Lar foi responsável pelo ensino fundamental de crianças com deficiência visual na Paraíba durante décadas. Contudo, com o advento das leis federais que obrigam as instituições de ensino regulares a aceitarem a matrícula de $\mathrm{PcD}$, a instituição passou a contribuir para a formação dos alunos do ensino fundamental, e não ser mais o responsável por essa atribuição. Apesar disso, o ensino das disciplinas regulares para alunos com deficiência visual ainda é oferecido no espaço físico da ONG. Além disso, diversos gestores e professores da ONG também atuam nas demais instituições de ensino da Paraíba, o que contribuiu para o desenvolvimento da pesquisa nesse ambiente.

A entrada no campo do primeiro autor foi realizada após o convite para ser professor voluntário na instituição, frequentando a ONG Lar duas vezes na semana. Dentre os diversos setores da ONG - biblioteca, área de estimulação precoce para bebês, consultório médico, odontológico e psicológico e setor de orientação e transcrição para o Braille -, o trabalho foi realizado no Setor Itinerante, onde é realizado o reforço escolar na leitura comum e em Braille.

Os dados foram coletados entre agosto de 2014 e setembro de 2015 através de observações participantes, entrevistas narrativas e entrevistas em profundidade (Figura 2). Após a entrada no campo, foi realizada uma coleta de dados inicial, que envolveu notas sobre o dia a dia dos alunos, as suas práticas de consumo e a maneira pela qual os alunos interagiam com os membros da ONG Lar. Buscou-se, nesse momento, a maior aproximação com os sujeitos de pesquisa, definir os objetivos deste estudo e, inclusive, identificar as demais técnicas de coleta necessárias para a compreensão do objeto de estudo.

Figura 2 - Etapas da coleta de dados

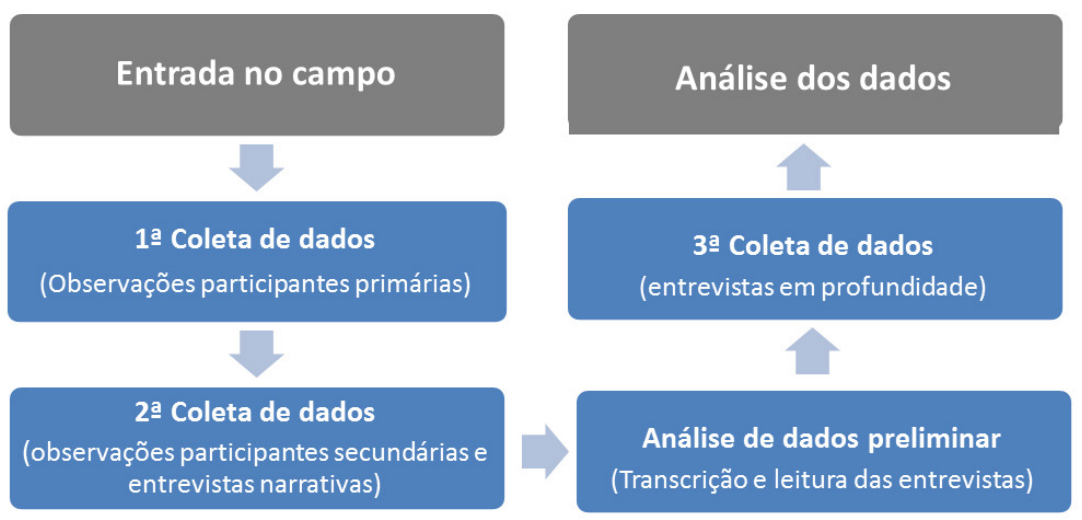

Fonte: Elaborado pelos autores (2017).

A despeito da dificuldade inicial em desenvolver "habilidades linguísticas" (ANGROSINO, 2009, p. 77) necessárias para compreender gírias e significados atribuídos à postura e à linguagem gestual, as observações participantes primárias foram essenciais para a realização das demais observações e das entrevistas. No segundo momento de observações 
participantes, as notas passaram a ser feitas com maior fluidez e direcionadas para o objeto de estudo. Todas as notas de campo foram feitas a partir do mesmo modelo e dentro da ONG Lar, mas em ambientes diferentes da instituição - recepção, refeitório, áreas de lazer, academia, ambiente dos professores, sala de informática e setor de Itinerância. 0 modelo de nota de campo utilizado foi baseado em Angrosino (2009), que destacou a importância de o observador realizar anotações sistemáticas e organizadas; descrever na ficha de nota a data, lugar e hora de observação; registrar o máximo possível de trocas verbais palavra por palavra; e descrever os objetos materiais objetivamente. Os dados foram coletados e registrados em um smartphone.

Em relação às entrevistas narrativas, optou-se por empregar esta técnica com 16 alunos do ensino fundamental diante da possibilidade de investigar a realidade desse grupo de consumo a partir de discursos individuais e estimular o sujeito entrevistado a contar algo sobre algum acontecimento importante de sua vida durante conversas informais (JOVCHELOVICH; BAUER, 2002; MUYLAERT et al., 2014).

Quadro 1 - Perfil dos alunos entrevistados

\begin{tabular}{|c|c|c|c|c|c|}
\hline Pseudônimo & Idade & Série & $\begin{array}{c}\text { Tipo de deficiência } \\
\text { visual }\end{array}$ & $\begin{array}{c}\text { Cidade onde } \\
\text { reside }\end{array}$ & Tipo de escola \\
\hline Ana & 8 & 20 & Totalmente Cega & João Pessoa & Pública \\
\hline Bruna & 10 & 40 & Cega de um olho & Guarabira & Pública \\
\hline Cláudia & 12 & 70 & Totalmente Cega & João Pessoa & Particular \\
\hline Denise & 11 & 50 & $\begin{array}{c}\text { Pequena percepção } \\
\text { luminosa }\end{array}$ & João Pessoa & Particular \\
\hline Elena & 15 & $8^{\circ}$ & Totalmente Cega & Sapé & Pública \\
\hline Fernanda & 9 & 40 & Baixa visão & João Pessoa & Pública \\
\hline Geórgia & 7 & 10 & Baixa visão & Santa Rita & Pública \\
\hline Hortência & 16 & 9o & Totalmente Cega & João Pessoa & Pública \\
\hline lara & 14 & 9o & Totalmente Cega & João Pessoa & Particular \\
\hline Joana & 9 & 40 & $\begin{array}{c}\text { Baixa amplitude } \\
\text { visual }\end{array}$ & João Pessoa & Particular \\
\hline Lauro & 10 & 3으 & Totalmente Cego & Santa Rita & Pública \\
\hline Mauro & 10 & 40 & $\begin{array}{c}\text { Pequena percepção } \\
\text { luminosa }\end{array}$ & João Pessoa & Particular \\
\hline Nando & 9 & 40 & Totalmente Cego & João Pessoa & Particular \\
\hline Otávio & 12 & 70 & Totalmente Cego & Sapé & Pública \\
\hline Paulo & 12 & 60 & $\begin{array}{c}\text { Pequena percepção } \\
\text { luminosa }\end{array}$ & João Pessoa & Púbica \\
\hline Queiroz & 13 & 80 & $\begin{array}{c}\text { Pequena percepção } \\
\text { luminosa }\end{array}$ & Bayeux & Pública \\
\hline
\end{tabular}

Fonte: Elaborado pelos autores (2017).

Os diálogos foram feitos em diferentes momentos com os mesmos sujeitos de pesquisa, em função da dificuldade de ter a atenção das crianças por muitos minutos - até mesmo em conversas informais. Foram feitas 93 entrevistas narrativas que tiveram 14 minutos de duração em média. 0 diálogo de menor duração durou 6 minutos e o mais longo, 31. O tamanho do roteiro de entrevista foi outro fator que justificou a condução das 
pequenas entrevistas em mais de um momento. Todas as entrevistas ocorreram dentro da instituição e foram realizadas antes, durante, no intervalo ou depois das aulas de crianças que frequentavam, no mínimo, semanalmente a ONG (Quadro 1).

Como se observa no Quadro 1, os sujeitos de pesquisa investigados residem na região metropolitana de João Pessoa, possuem entre 7 e 16 anos e, em sua maioria, não iniciaram os estudos na idade ideal ou repetiram alguma série, o que justifica a disparidade entre as idades dos alunos e suas séries. Elena, por exemplo, é uma aluna com 15 anos e, portanto, já deveria estar cursando o ensino médio, mas ainda se encontra no fundamental.

Depois de realizar as observações participantes e as entrevistas narrativas, foi iniciada a coleta por meio de entrevistas em profundidade com colaboradores da ONG Lar. Enquanto a entrevista narrativa foi adotada por ser uma técnica capaz de evidenciar aspectos nebulosos da realidade de um grupo de consumo, a partir de discursos individuais coletados em uma situação rotineira do entrevistado (JOVCHELOVICH; BAUER, 2002), as entrevistas em profundidade foram conduzidas em função de sua aplicabilidade quando 0 objetivo da investigação exige que se compreenda com profundidade o mundo no qual vivem os sujeitos, particularmente quando eles são difíceis de ser recrutados (GASKELL, 2002).

A análise preliminar evidenciou que diversos aspectos relacionados ao comportamento de consumo de deficientes visuais durante o ensino fundamental não tinham sido relatados nas entrevistas narrativas, mas foram descritos nas notas de campo, pois eram complexos para as crianças (como a cobrança de taxas extras) ou estavam relacionados a decisões específicas dos responsáveis pelos alunos (a decisão de matrícula, por exemplo). Nesse sentido, entrevistar outros atores pareceu ser essencial e foram realizadas entrevistas inicialmente com dois professores, quatro profissionais que atuavam na instituição. Todos os entrevistados eram profissionais com experiência mínima de cinco anos no atendimento ao deficiente visual, que possuem formações distintas e diferentes lentes sobre a inclusão escolar (Quadro 2).

Quadro 2 - Perfil dos colaboradores da ONG Lar entrevistados

\begin{tabular}{|c|c|c|c|c|c|c|}
\hline Pseudônimo & Idade & $\begin{array}{c}\text { É deficiente } \\
\text { visual? }\end{array}$ & Profissão & $\begin{array}{c}\text { Há quanto } \\
\text { tempo trabalha } \\
\text { na ONG? }\end{array}$ & $\begin{array}{l}\text { Trabalha em } \\
\text { qual outra } \\
\text { instituição? }\end{array}$ & É voluntário? \\
\hline Alana & 32 & Não & $\begin{array}{l}\text { Professora de } \\
\text { Inglês }\end{array}$ & 5 anos & $\begin{array}{l}\text { Sim, escola } \\
\text { pública }\end{array}$ & Não \\
\hline Beatriz & 51 & $\operatorname{sim}$ & Psicopedagoga & 16 anos & - & Não \\
\hline Carla & 27 & Não & Pedagoga & 1 ano & $\begin{array}{l}\text { Sim, escola } \\
\text { particular }\end{array}$ & Sim \\
\hline Daiane & 43 & Sim & $\begin{array}{l}\text { Coordenadora } \\
\text { pedagógica }\end{array}$ & 11 anos & - & Não \\
\hline Edison & 54 & Não & Assistente Social & 22 anos & Sim, outra ONG & Não \\
\hline Fábio & 33 & Sim & $\begin{array}{l}\text { Professor de } \\
\text { informática }\end{array}$ & 8 anos & $\begin{array}{l}\text { Sim, escola } \\
\text { pública }\end{array}$ & Sim \\
\hline
\end{tabular}

Fonte: Elaborado pelos autores (2017). 
A partir da leitura do Quadro 2, nota-se que metade dos entrevistados são deficientes visuais. Aliás, dos 22 funcionários da ONG, 10 deles são pessoas com deficiência. Alguns deles, inclusive, foram alfabetizados na instituição e regressam para ela trabalhando como voluntário ou não. Fábio, por exemplo, é professor voluntário e foi alfabetizado na instituição. Por fim, foram realizadas cinco entrevistas em profundidade com responsáveis de alunos da instituição (Quadro 3).

Quadro 3 - Perfil dos responsáveis pelos alunos entrevistados

\begin{tabular}{|cccccc|}
\hline Pseudônimo & Idade & $\begin{array}{c}\text { Responsável por } \\
\text { qual(is) aluno(s)? }\end{array}$ & $\begin{array}{c}\text { Grau de } \\
\text { parentesco }\end{array}$ & Profissão & $\begin{array}{c}\text { É o responsável } \\
\text { pela matrícula na } \\
\text { escola? }\end{array}$ \\
\hline Ágata & 39 & lara & Tia & Dona de casa & Sim \\
Bianca & 44 & Elena e Otávio & Mãe & Diarista & Sim \\
Célia & 29 & Mauro & Mãe & Dona de casa & Sim \\
Diana & 32 & Nando & Mãe & Professora & Sim \\
Eleno & 68 & Fernanda & Avô & Aposentado & Não \\
\hline
\end{tabular}

Fonte: Elaborado pelos autores (2017).

Os cinco entrevistados são pessoas que frequentemente levam as crianças para a ONG Lar e ficam nas dependências da instituição até que as atividades sejam encerradas (Quadro 3). As entrevistas com os profissionais da ONG Lar e com os responsáveis duraram em média uma hora. A dificuldade de encontrar horários compatíveis foi amenizada pelo interesse dos respondentes e pelo incentivo da vice-presidente da ONG Lar.

O roteiro utilizado nas entrevistas narrativas abordou a vulnerabilidade do consumidor - pressões, estado de vulnerabilidade, eventos disparadores e resiliência - (BAKER et al., 2001; BAKER et al., 2005; BAKER; MASON, 2012), a atuação do deficiente visual enquanto consumidor - experiência e barreiras para o consumo, produtos de tecnologia assistiva e as estratégias de locomoção em servicescapes - (CHILDERS; KAUFMAN-SCARBOROUGH, 2009; KAUFMAN-SCARBOROUG; CHILDERS, 2009; WORTH, 2013; FARIA et al., 2014; YU et al., 2015) e os serviços educacionais para o deficiente visual - formação do autoconceito na escola, barreiras arquitetônicas, pedagógicas e atitudinais e o papel da família e dos professores - (MANTOAN, 2002; DALL'ACQUA, 2002; MANTOAN, 2003; RAMOS, 2007; SMEHA; SEMINOTTO, 2008; COUTINHO, 2011; PASCHOAL et al., 2014).

Para as entrevistas em profundidade, poucas alterações foram feitas. Apenas foram adicionados quatro questionamentos relacionados ao processo de escolha das escolas (MANTOAN, 2002), à percepção dos pais de alunos videntes sobre a inclusão escolar (COUTINHO, 2011), à cobrança de taxas extras e à decisão de abandono da escola (MANTOAN, 2002 ; 2003). Ressalta-se que os roteiros orientaram os diálogos, mas novas dimensões emergiram a partir da análise dos dados.

Os dados foram analisados segundo a "Espiral de análise de dados" desenvolvida por Creswell (2007) e adotada por Tureta (2011), outro estudo etnográfico realizado na área de Administração. A análise foi iniciada com a reunião de todas as informações coletadas na pesquisa e a organização das informações em pastas, onde as entrevistas narrativas de 
diferentes datas foram agrupadas em um único arquivo, a fim de juntar as respostas do mesmo respondente. Em seguida, foi feita a leitura das transcrições e das notas de campo para facilitar o processo de exploração das informações, sendo possível obter noção geral dos dados antes que eles fossem "reduzidos" a códigos.

A partir de então, foram criados códigos que permitiram a identificação de temas em comum nos materiais coletados. Depois de comparados, os principais temas foram identificados e o material foi lido novamente com o objetivo de fazer interpretações à luz da teoria utilizada e agrupá-los em subtópicos. Em seguida, os subtópicos foram agrupados em tópicos. O processo de análise dos dados foi encerrado com a validação dos resultados pelos gestores e professores da ONG Lar entrevistados - member checks.

Antes de iniciar a discussão dos achados do estudo etnográfico, é importante destacar que as crianças que participaram do estudo foram autorizadas por seus pais, que deram permissão para a gravação dos diálogos com seus filhos. Alguns pediram para ler o roteiro de entrevista e outros perguntaram se as identidades das crianças seriam preservadas. Os demais respondentes - responsáveis dos alunos e colaboradores da ONG - também foram informados que suas identidades seriam preservadas, bem como o nome da própria ONG. Não houve recompensa financeira para a participação da pesquisa.

Ainda devem ser destacadas limitações da coleta de dados e aspectos positivos da experiência. Antes de começar a investigação na ONG Lar, buscou-se o contato com nove escolas da rede pública e privada de ensino. Em todas as ocasiões, as respostas foram negativas sobre a possibilidade de conduzir a etnografia dentro dos espaços da escola. Contudo, um aspecto positivo a ser destacado é que a aproximação entre o primeiro pesquisador e os sujeitos de pesquisa possibilitou uma ampla coleta de dados - 121 laudas de entrevistas narrativas, 95 laudas de entrevistas em profundidade e 60 páginas de notas de campo digitadas em Times New Roman 12 descritas a seguir.

\section{ACHADOS DO ESTUDO ETNOGRÁFICO}

Este tópico traz a análise dos principais achados deste estudo. Primeiro, irei tratar das primeiras experiências na escola dos alunos - o processo de matrícula e os primeiros dias de aula. Em seguida, abordarei abordaremos a rotina nas escolas, com ênfase nas interações das crianças com os seus professores, os colegas de sala e os gestores de suas escolas. Por fim, discutirei o papel da família e das ONGs em relação às práticas de consumo dos alunos. Essa divisão resultou da Espiral de análise de dados descrita anteriormente, ou seja, os tópicos abaixo não foram previamente estabelecidos e derivam do processo de codificação, classificação, agrupamento e análise do material coletado.

\subsection{PRIMEIRAS EXPERIÊNCIAS NA ESCOLA}

O primeiro contato das crianças brasileiras com os serviços educacionais pode ser iniciado nos três primeiros anos de vida, caso a criança frequente escolas/creches públicas ou privadas. Nos anos seguintes, entre os 4 e 6 anos de idade, espera-se que o aluno participe da pré-escola e termine a educação infantil, dando início ao ensino fundamental 
(GORNI, 2007). No caso da criança cega ou que possua visão subnormal, a educação infantil deve ser complementada pelo suporte de centros de atendimento responsáveis pelo início da estimulação sensorial e motor. Há especificidades e barreiras vivenciadas pelas crianças e seus responsáveis para o consumo de tal serviço educacional desde o processo de decisão da matrícula, descrito a seguir.

A matrícula dos alunos com deficiência visual, apesar de ser garantida por lei, é um processo árduo e desgastante para os responsáveis por esses alunos. 0 medo de expor as crianças ao convívio com as demais pessoas videntes - professores, alunos e gestores educacionais - é um dos fatores que exerce influência na decisão da matrícula ou não do aluno, visto que, na perspectiva dos responsáveis pelos alunos, as crianças não estão preparadas para lidar sozinhas com o estigma que possuem. O receio em deixá-las no ambiente escolar sem os seus olhares provocou, em diversas situações, o retardo na matrícula dos alunos.

Querer eu queria [matricular o aluno], não é? Mas achava que iam judiar dele. Já basta o que eu sofro em casa, meu filho. Até os tios dele têm pena dele, conseguem nem colocar no colo [...]. Quando chegou a hora de colocar na escola e vi aquela quantidade de menino, desisti (DIANA, mãe).

Fiquei com medo sim, não vou mentir. Principalmente, quando foi a vez da Elena, a mais nova. Achava que os professores iam deixar ela encostada num canto. Com o Otávio foi mais fácil, já sabia como funcionava. Mas a Elena perdeu um ano por isso... Eu tinha medo (BIANCA, mãe).

Além do receio dos pais, os representantes das escolas apresentaram diversas justificativas para dificultar a matrícula dos alunos com deficiência. Nas escolas públicas, o argumento mais comum foi a falta de vagas. Os pais também foram desmotivados pelos gestores educacionais e professores por meio de relatos negativos sobre a estrutura física e de pessoas das escolas.

Nas escolas particulares também foram relatadas dificuldades durante o processo de matrícula, como se observa:

[...] já foram logo dizendo que eu tinha que pagar isso e aquilo. Começou a aparecer tanta taxa [...]. Sim, na matrícula. Falaram que ia aumentar os gastos da escola com o material didático, que precisariam contratar mais gente, ajeitar as salas. Como se não já fosse obrigação deles (DIANA, mãe).

Cobraram sim. E eu paguei, não é? Era a única [escola] perto da minha casa que eu confiava. Conhecia a professora, então valia a pena pagar mais. A gente conhece a lei, sabe que eles não podem cobrar. Mas também pensa no futuro do nosso filho, quer o melhor pra ele [...]. E essas coisas demoram (CÉLIA, mãe).

As cobranças abusivas mencionadas não são realizadas apenas durante a matrícula, mas as escolas também pressionam os responsáveis pelos alunos a pagarem taxas mensais relativas aos "custos extras" da permanência de um aluno com deficiência visual. De acordo com os responsáveis pelas escolas, o pagamento é necessário para que a escola contrate profissionais especializados e compre materiais pedagógicos voltados para tais alunos. No 
entanto, tal prática é ilegal, de acordo com o Estatuto da Pessoa com Deficiência de 2015, que prevê punição de até cinco anos para tais infratores (BRASIL, 2015).

Depois de tomarem a decisão de matricular as crianças e encontrarem uma escola capaz de contribuir para a formação desses alunos, um novo cenário surge para as crianças e seus pais durante os primeiros dias de aula. A aproximação com novos colegas (videntes e deficientes visuais); a necessidade de reconhecimento e adaptação à estrutura física da escola; e o contato com os professores são algumas novidades que fazem parte deste processo.

Na perspectiva dos responsáveis pelos alunos, trata-se de uma fase marcada pela angústia, pois é uma das primeiras situações em que as crianças são colocadas em um ambiente sem a presença de um familiar. 0 medo da reação dos demais alunos e a desconfiança da capacidade da escola de promover a inclusão educacional justificam o sentimento de angústia da família. Alguns familiares, inclusive, não foram capazes de deixar seus filhos na escola e permaneceram nas instituições até o fim das aulas. 0 depoimento de Bianca ilustra os sentimentos envolvidos neste momento para a família:

Eu não conseguia ir pra casa, ficava olhando como ela se comportava, se tava brincando com os coleguinhas. Ela se comportava muito bem, não dava trabalho em nada... Era mais quieta que os outros... Muito mais. O problema era comigo mesmo. Ficava achando que alguma coisa ruim ia acontecer com ela, alguém ia maltratar ela (BIANCA, mãe).

A transcrição acima está alinhada às conclusões de Oliveira (2007), que encontrou resultados similares aos deste estudo. Para as crianças entrevistadas, o primeiro contato com os seus colegas de classe foi um momento desafiador que ocorreu, geralmente, com o incentivo das professoras. Algumas dinâmicas de socialização - como as atividades de desenho em dupla, pinturas coletivas e as brincadeiras coletivas com massinha - contribuíram para a aproximação dos alunos. Em outros casos, prevaleceu a falta de sensibilidade dos docentes diante da deficiência - similar ao cenário relatado em Leite (2013) e Coelho, Orsini e Abreu (2016). Foi pedido para que as crianças descrevessem objetos, falassem de si, caminhassem fora da sala de aula para conhecer as dependências da escola ou desenvolvessem outras atividades que inibiram a participação dos alunos entrevistados.

Parte das crianças exprimiram insegurança e vergonha para descrever os eventos negativos, além de medo da represália dos professores. Portanto, tais relatos só foram obtidos no final da coleta de dados deste estudo, quando já havia uma maior aproximação entre entrevistador e entrevistado.

[...] não fiquei triste na hora, só depois. Conversei com "mainha" e ela me acalmou mais... Então eu voltei [para escola] no outro dia. Mas fiquei triste, porque a professora disse na sala que era pra todo mundo ter cuidado comigo, cuidado pra não esbarrar em mim. Disse que todo dia alguém ia anotar as tarefas na minha agenda. E não falava comigo, falava com os outros. Como se eu não tivesse na sala (JOANA, aluna). 
Na primeira semana a professora disse que a turma ia receber uma aluna "ceguinha". Eu tenho nome e não gosto quando me chamam disso (FERNANDA, aluna).

O primeiro relato ilustra uma prática nociva do mercado já abordada por Damascena e Farias (2013) e Coelho e Abreu (2015): a crença de que a PcD é invisível nos ambientes de serviço. Assim como os varejistas de supermercados e de shopping centers, alguns docentes também ignoraram a presença dos alunos com deficiência visual e direcionaram o discurso para as demais pessoas videntes presentes no mesmo ambiente. Além de ignorá-los, o relato evidencia outra prática recorrente na sociedade brasileira: a utilização de diminutivos para descrever pessoas com deficiência. Ao invés de exprimir carinho e respeito, tal prática (como foi o caso do relato de Ana) exprime pena ao aluno e assume um caráter depreciativo.

Após o período de adaptação à nova instituição de ensino, alguns atores, como os demais alunos, os professores e gestores escolares, exercem um importante papel diante do consumo de serviços educacionais dentro das escolas. O dia-a-dia nas escolas será descrito a seguir, portanto, em função da interação dos alunos e de seus responsáveis com esses atores.

\subsection{EXPERIÊNCIAS NO DIA A DIA DA ESCOLA}

Houve a oportunidade de conversar informalmente com crianças, adolescentes e adultos deficientes visuais durante o trabalho na ONG Lar. A despeito das queixas sobre os serviços educacionais oferecidos pelas escolas, um aspecto positivo que sempre me chamou atenção foi a quantidade de relatos de amizade que escutei dos alunos sobre os colegas de suas escolas. Aparentemente, eles são responsáveis diretos não somente pelo acolhimento e integração dos alunos, mas também pelo rendimento escolar dos alunos com deficiência.

No contexto investigado, apenas um aluno possuía acompanhante em sala de aula. Diante disso, os demais alunos são essenciais para a compreensão do conteúdo em sala de aula pela criança cega ou com baixa visão, uma vez que os alunos videntes podem realizar um rodízio para anotar o que for necessário; ajudá-los nas dinâmicas e atividades em sala; e reler o enunciado dos exercícios.

Faço todas as atividades normalmente, às vezes faço sozinha... Se eu tiver o livro em Braille já faço a tarefa em casa, vou na ONG Lar e eles escrevem "tudinho" e depois mostro pra tia. Acostumei [...]. Às vezes, preciso de alguém pra ler os textos pra mim, então peço pros meus colegas. Sempre tem um pra ler ou escrever o que eu preciso, eles revezam (IARA, aluna).

[...] consigo entender o que está escrito, se tiver com letra grande. Quando não dá, tiro dúvida com as meninas e consigo fazer (FERNANDA, aluna).

Além da realização de exercícios, os professores do ensino fundamental também organizam brincadeiras para os alunos durante e no intervalo das aulas. Esses momentos de descontração e interação são fundamentais para as crianças com deficiência, pois podem 
contribuir para a sua integração com os demais alunos e deixá-las mais confortáveis no ambiente escolar. Contudo, algumas brincadeiras realizadas dentro da sala de aula podem parecer sem graça para o aluno deficiente visual, caso a brincadeira envolva algum brinquedo que a criança não saiba como utilizá-lo.

Eu não brincava, porque achava sem graça. Não entendia o que eles estavam fazendo, não conseguia ver os desenhos... Era chato (NANDO, aluno).

Eles estavam fazendo alguma brincadeira que precisava correr e depois tinha que escrever na lousa. Fiquei só assistindo (FERNANDA, aluna).

Os professores podem direcionar a turma para atividades que sejam interessantes para todos os alunos, além de selecionar brinquedos mais atrativos para $\mathrm{PcD}$ - com cores luminosas (vermelho, amarelo, laranja) ou grandes contrastes (amarelo e preto, preto e branco); sonoros; ou com texturas diferentes, como mencionado em Paschoal et al. (2014).

Minha experiência na ONG Lar fez com que eu percebesse que, em muitas situações, o professor está disposto a ajudar o aluno a aprender, mas não sabe como. De fato, o aluno com deficiência visual precisa de materiais especiais que permitam o seu aprendizado, como livros e exercícios em Braille, máquina de escrita em Braille (ou textos em fonte Arial 24 e cadernos com pautas largas, caso a criança apresente baixa visão). As provas também têm de ser adaptadas, de acordo com a necessidade do aluno. Contudo, apenas duas escolas (uma particular e outra pública) do contexto investigado possuem os materiais mencionados acima. Observei que os professores adotaram estratégias alternativas para suprir a necessidade dessas ferramentas.

Dou aula em Mangabeira, na escola que eu ensino não tinha DOSVOX [sistema operacional que permite a utilização de computadores para pessoas cegas desempenharem tarefas diversas]. Era difícil explicar pra um aluno cego o que é um computador e pra quê ele serve, se ele não podia utilizá-lo. Então, pesquisei algumas na Internet algumas ferramentas de ensino que me ajudaram. Meus alunos utilizavam o computador convencional e eu pedia para um aluno vidente dizer o que tinha na tela. Ou então, na maioria das vezes, eu levava meu notebook para a sala e dava a aula pra eles (FÁBIO, professor).

Além dos professores, os gestores das escolas exercem grande influência no comportamento de consumos de estudantes do ensino fundamental. De fato, é tarefa árdua direcionar a atenção para PcD e disponibilizar recursos financeiros para a inclusão desses alunos, visto que as $\mathrm{PcD}$ são percebidas pelo mercado como consumidoras de baixo poder aquisitivo e capazes de comprometer o rendimento da escola nas avaliações governamentais (GORNI, 2007; SMEHAL; SEMINOTTO, 2008).

Essa percepção negativa desencadeou diversas ações que comprometeram o consumo dos serviços educacionais e levou os sujeitos de pesquisa deste estudo a vivenciarem situações de vulnerabilidade de consumo. A partir das observações e da análise dos relatos, percebi que a intensa concorrência das escolas particulares levou muitos proprietários e diretores de escola a desconsiderarem os seus alunos que possuem deficiência visual. Em alguns casos, professores e coordenadores pedagógicos apresentaram demandas relaciona- 
das à inclusão, mas tais demandas não foram atendidas. 0 argumento de que os recursos financeiros são limitados foi geralmente utilizado, como os relatos abaixo evidenciam:

Ele [diretor da escola] praticamente riu da minha cara. Mostrou o valor da conta de luz e perguntou se eu tinha dinheiro pra pagar por isso tudo, porque ele não tinha (FÁBIO, professor).

Infelizmente, não há uma cultura de inclusão das escolas e João Pessoa. Nossa batalha é grande e antiga, mas é difícil você colocar na cabeça de dono de escola que não tem a ver com bondade, caridade... Nada disso. É a lei. É a obrigação dele e dos outros donos de escola. Mas o argumento da falta de recursos é sempre utilizado... Dizem que o governo devia enviar dinheiro pra eles (DAIANE, coordenadora pedagógica).

Na perspectiva desses gestores, os investimentos em acessibilidade devem ser custeados pelo Estado e os professores devem por si próprios buscarem capacitação pedagógica para ensinar alunos com deficiência. No caso dos gestores de escolas públicas, a dificuldade em obter dinheiro e operacionalizar projetos são alguns dos argumentos utilizados. A inclusão desse grupo de alunos não é vista como prioritária, uma vez que, assim como os gestores de colégios particulares, os responsáveis pelas instituições educacionais públicas entendem que o contingente de alunos deficientes não justifica os gastos que deveriam ser realizados. Os relatos de Eleno e Célia ilustram os desafios que os responsáveis pelos alunos precisam enfrentar diante da realidade na escola pública e privada, respectivamente:

Minha neta disse que tava querendo estudar geografia e não tinha como... Porque na escola não tinha ninguém pra ler [...]. E eles não vão mudar, não vão colocar ninguém [...]. É triste escutar isso e não poder fazer nada (ELENO, avô).

[...] [A proprietária da escola] disse que não tinha condições de comprar os livros em Braille, a máquina de escrever, colocar o DOSVOX... Nada. Disse que, se fosse escutar os pedidos de todos os pais, a escola ia fechar (CÉLIA, mãe).

A aproximação dos diretores de escola com ONGs que atendem PcD é uma possível maneira de aumentar o conhecimento sobre o assunto e promover a inclusão escolar. Nessas organizações civis, há profissionais de diversas áreas que possuem conhecimento acadêmico e longa vivência com alunos deficientes, o que os tornam aptos a assessorarem os gestores escolares e apontarem quais mudanças devem ser feitas. No contexto analisado, as ONGs agem como agentes catalisadores de mudança (BAKER; MASON, 2012), de modo a mitigar as situações de vulnerabilidade vivenciadas pelos alunos.

Depois de tratar das experiências dos alunos no ambiente escolar, dois atores que interferem no consumo desse serviço educacional são abordados: a família e as ONGs. Trata-se de uma discussão que dará ênfase aos elementos externos à escola que influenciam diretamente nas práticas de consumo dos alunos deficientes visuais. Outros atores interferem no consumo deste serviço, como o próprio Estado. Contudo, os subtópicos que emergiram da análise de dados foram os dois mencionados. 


\subsection{EXPERIÊNCIAS ALÉM DA ESCOLA: O PAPEL DA FAMÍLIA E DAS ONGS}

As dificuldades durante a matrícula dos alunos e nos primeiros dias de aula do ensino fundamental são alguns dos desafios iniciais enfrentados pelos familiares de crianças com deficiência visual. A maneira pela qual os familiares lidam com essas e as demais dificuldades no consumo de serviços educacionais está relacionada à formação no ensino básico dos alunos, visto que esse ambiente ainda é marcado pela falta de profissionalismo e respeito às leis.

Ao dialogar com as crianças, encontrei indícios de que irmãos e primos, pela proximidade de idade, são familiares que podem interferir diretamente no rendimento escolar dos alunos e nas suas práticas de consumo, visto que, em algumas situações, são esses familiares que ajudam nas lições de casa, acompanham as crianças até as escolas e convivem com mais proximidade com as crianças. Essa influência parece ser maior ainda quando os irmãos e primos dos alunos deficientes estudam na mesma escola. Contudo, a relação pode ser positiva, quando o familiar ajuda a criança, interage frequentemente com ela e assume o papel de protetor, ou negativa, quando ele simplesmente ignora o familiar ou possui vergonha. 0 excesso de proteção de algumas mães, inclusive, foi apontado por Beatriz como outro elemento que inibe a formação dos alunos.

É o espírito de mãe mesmo, a gente que ajudar, proteger... E não sabe como. Às vezes atrapalha, ao invés de ajudar. Muitas vezes. Tem mãe aqui que prefere fazer as tarefas do filho do que ver ele reprovando. Uma vez eu descobri, mas nosso papel não é brigar, criticar. É mais importante esclarecer pra família que as dificuldades existem e vão continuar existindo na escola, e o aluno tem que ser capaz de fazer suas atividades com independência [...]. Pedir ajuda é normal, errado é fazer pelo filho (BEATRIZ, psicopedagoga).

Além do medo das crianças repetirem o ano, em alguns momentos eu percebi que o excesso de proteção dos responsáveis se estende às atividades físicas. A despeito da existência de uma série de esportes adaptados e voltados para deficientes visuais, parte das famílias desmotiva as crianças a participarem dessas atividades.

Outro elemento evidenciado na coleta de dados foi o nível de informação da família sobre a deficiência. 0 acesso às redes sociais virtuais, por exemplo, é relevante para a difusão de informações relativas à inclusão escolar entre os pais, que compartilham suas experiências nesses espaços virtuais. Tanto os alunos quanto os seus pais utilizam esses canais de comunicação - principalmente o Facebook - para conversar com outros deficientes e ficarem atualizados sobre a legislação voltada para $\mathrm{PcD}$, as atividades artísticas e esportivas desenvolvidas e as novas tecnologias direcionadas e esse grupo de consumidores. No caso dos familiares, essa interação pareceu ser positiva para eles, pois também foi capaz de informá-los sobre questões relativas à educação dos alunos.

Eles postam lá [no grupo do Facebook] fotos dos meninos jogando basquete de cadeira de rodas e outros esportes... É muito bacana. [...]. Num desses posts, descobri que tinha uma escola aqui em João Pessoa que estava sendo 
processada, por negar a matrícula a um aluno. Compartilhei na hora, a gente tem que ter se defender (ÁGATA, tia).

Quando os familiares buscam informações sobre a deficiência, passam a compreender como podem, de fato, contribuir para a formação dos alunos. Ao interagir com maior frequência com os pais de outros alunos com deficiência e conseguirem maior suporte emocional, novas soluções são identificadas para melhorar o desempenho educacional dos alunos.

Em relação às ONGs, um benefício comum das instituições é o de prestar esclarecimentos iniciais sobre a deficiência de seus usuários e conscientizar seus familiares sobre as verdades e os mitos relativos à condição dos novos frequentadores. A fala de Edison sugere que, por geralmente possuir um corpo de funcionários com diferentes especialidades, esses espaços oferecem aos pais e demais familiares das crianças importantes esclarecimentos para aqueles que têm pouco conhecimento sobre a vida de deficiente visual.

Eles chegam aqui cheios de dúvidas, quase sempre muito abalados. No primeiro momento, nosso papel é muito mais de acolher, acalmar e mostrar pra ele que não é o fim do mundo. Pelo contrário, é o início de uma vida de desafios, mas muito prazerosa. Conviver com pessoas que nos surpreendem diariamente é muito bom [...]. Mas o começo é difícil, claro. Tem a vergonha, o medo, a raiva até. Tem sim tudo isso (EDISON, assistente social).

Achei que era o fim do mundo, que meu filho ia passar o dia em casa, pro resto da vida. Sem aprender nada. A gente estuda, sabe que não é assim. Mas, quando acontece com a gente, é diferente, viu? Quem me acolheu foi a XXX [ex-presidente da ONG LAR], me explicou tudo (DIANA, mãe).

O relato de Diana ilustra um sentimento comum entre a maioria dos responsáveis dos alunos: o desespero perante a descoberta da deficiência. 0 enfrentamento das dificuldades impostas pela cegueira ou baixa visão, portanto, é um processo árduo que pode ser amenizado com o suporte das ONGs e dos demais familiares. Apesar de a conscientização dos familiares está aumentando nas últimas décadas, a partir do que foi observado, o contato com tais organizações ainda contribui nesse momento.

Outro benefício oferecido pelas ONGs é a possibilidade de aproximação entre as crianças com deficiência e de seus familiares para o compartilhamento de informações e a aceitação da deficiência. Ademais, durante o ensino fundamental o aluno deficiente visual passa a desenvolver atividades com maior independência na escola. Desse modo, a realização aulas sobre AVD (Atividades da Vida Diária), que geralmente não são oferecidas nas escolas, é essencial para os alunos, pois os alunos são incentivados a realizar simples atividades do cotidiano de maneira independente, como calçar os sapatos, se deslocar com a bengala, utilizar talheres etc.

Vale ressaltar que, além dos serviços oferecidos pelas ONGs, as crianças buscaram formas de lidar com a deficiência nas escolas com criatividade e resiliência. Identificar professores capazes de ajudá-los, explicar as limitações que possuem para os colegas de classe e obter informações nas redes sociais foram algumas formas encontradas para lidar com suas limitações. Assim como outros estudos constataram (KAUFMAN-SCARBOROUGH; 
CHILDERS, 2009; FARIA; SILVA, 2012; FARIA; MOTTA, 2012), a deficiência visual não impede esse grupo de consumo de se vestir bem, cuidar da sua aparência, valorizar experiências de consumo e marcas específicas de produtos, além de promover boca-a-boca positivo ou negativo.

Aparentemente, os achados desta pesquisa possuem maior relevância para a área de Educação do que para Marketing. Entretanto, partimos do entendimento de que a escola é um espaço onde diversos serviços são ofertados e que os alunos com deficiência visual são consumidores repletos de direitos instituídos na legislação brasileira. Entender as práticas de consumo desses alunos sob o olhar da TCR, portanto, nos levou a compreender que as falhas desse serviço educacional iniciam desde o processo de matrícula das crianças e se estendem durante o contato dos alunos com professores e gestores escolares.

\section{CONSIDERAÇÕES FINAIS}

É atribuição dos acadêmicos de marketing estudar o consumo com vistas para o bem-estar individual e coletivo. Vinculados ou não à abordagem transformativa, tais pesquisadores são capazes de oferecer um novo olhar sobre serviços diversos, como o ensino fundamental. Dessa forma, este estudo teve por objetivo analisar o consumo de serviços educacionais durante o ensino fundamental por deficientes visuais, onde foram elencados quatro objetivos secundários para o seu alcance.

Buscou-se, inicialmente, investigar as práticas de consumo dos consumidores com deficiência visual ao usufruírem de serviços educacionais durante o ensino fundamental. Os resultados apontam que tais práticas são iniciadas antes do início das aulas, pois, além do receio comum de todo pai em escolher a escola ideal para os seus filhos, a dificuldade em encontrar escolas adequadas para crianças com deficiência visual é maior - o que levou outros atores a participarem da decisão de matrícula, como gestores e professores de ONGs e pais de outras crianças com deficiência.

Em seguida, foi investigado o papel de familiares, da comunidade escolar e das ONG em relação ao comportamento de consumo de deficientes visuais ao usufruírem de serviços educacionais durante o ensino fundamental. A partir da análise dos dados, constatou-se que a família exerce influência no desempenho dos alunos, no autoconceito que as crianças possuem, no senso de dependência no ambiente escolar. Porém, a família também pode atrapalhar o processo inclusivo e ser um elemento que incentive os alunos a desistirem das escolas. Alguns relatos demonstraram que os próprios pais de alguns alunos não acreditam no potencial de seus filhos e consideram que o esforço para os educar não será útil. De maneira similar, o ambiente escolar também pode promover a inclusão dos alunos ou ser um espaço de práticas exclusivas, que se manifestam por professores e diretores de escola despreparados. Já as ONGs, sob o ponto de vista dos responsáveis dos alunos, promovem o esclarecimento de informações sobre a educação das crianças; a interação entre alunos deficientes visuais e de seus familiares; o contato entre os responsáveis, que compartilham dúvidas e frustações; e o encaminhamento para as escolas do ensino fundamental.

Buscou-se, ainda, identificar as pressões e os estados de vulnerabilidade de consumo vivenciados pelos deficientes visuais ao usufruírem de serviços educacionais durante 
o ensino fundamental. O contexto pelo qual o deficiente visual está inserido exerceu maior influência sobre as suas práticas de consumo do que a deficiência em si. A impotência diante da cobrança de taxas abusivas, a falta de vagas em escolas públicas ou privadas e a ausência de materiais didáticos adequados são características do contexto investigado que acentuam o estado de vulnerabilidade dos entrevistados.

Por fim, objetivou-se compreender a percepção dos alunos sobre o consumo de serviços educacionais durante o ensino fundamental. Sob a ótica dos sujeitos de pesquisa investigados, o consumo de serviços educacionais pode ser algo negativo, que acentue 0 autoconceito negativo e o senso dependência que possuem, ou o contrário. Percebeu-se que a entrada e a permanência dos alunos nas escolas podem ser momentos marcantes positivamente para eles, pois há um esforço em identificar estratégias de comunicação e interação dentro e fora da sala de aula e uma maior aproximação com pessoas da mesma idade. Realizar as atividades passadas pelos professores é uma forma do próprio aluno perceber que é capaz de possuir autonomia e usufruir dos serviços educacionais.

Em se tratando das contribuições teóricas, transformativas e gerenciais deste estudo, iniciar o debate em marketing sobre a prestação de serviços educacionais no ensino fundamental foi um avanço teórico desta pesquisa. A despeito da vasta literatura nacional voltada para a compreensão do comportamento de consumo em shopping centers, serviços turísticos e restaurantes, não foram identificados estudos prévios em marketing que tratam deste tipo serviço e oferece um olhar diferente das publicações em Educação, uma vez que as práticas de consumo foram investigadas desde o processo de matrícula até a decisão de permanência ou saída da escola, no sentido de outras investigações em Educação (MANTOAN, 2002; 2003; SANTOS; VIEIRA, 2006; RAMOS, 2007; LEITE, 2013), que focam na sala de aula.

Cabe ainda ressaltar que a análise do objeto de estudo a partir da vulnerabilidade do consumidor, ao que parece, é outra iniciativa pioneira no Brasil. De acordo com a teoria da vulnerabilidade e resiliência do consumidor, cinco elementos devem ser considerados nesse processo: os fatores de risco (pressões), os eventos disparadores, o estado de vulnerabilidade, o pós-choque e os stakeholders do estado de vulnerabilidade e resiliência dos consumidores (BAKER; MASON, 2012). Os resultados da pesquisa indicam que as forças macroambientais (ambiente legal e tecnológico), familiares (pais, irmãos e demais parentes que levam as crianças para escolas ou participam da decisão de matrícula) e comunitárias (professores, colegas e diretores da escola) interferem na ocorrência de situações de vulnerabilidade dos alunos. Alguns eventos disparadores foram destacados, como o momento da decisão de matrícula, os primeiros dias de aula e o contato com professores e diretores sem preparo. 0 estado de vulnerabilidade foi manifestado pelos alunos e seus responsáveis, diante da impotência perante as práticas do mercado. O pós-choque ocorreu quando os agentes públicos de educação e as próprias escolas reforçaram as práticas excludentes dos eventos disparadores. Contudo, outros stakeholders, como as ONGs, agiram como agentes catalisadores de mudança, promovendo a inclusão dos alunos.

Em relação às implicações transformativas, esta investigação foi construída em conformidade com o processo de pesquisa transformativa descrito por Crockett et al. (2013), como se observa no Quadro 4. 
Quadro 4 - Processo de pesquisa transformativa X Processo de pesquisa adotado

\begin{tabular}{|c|c|c|}
\hline Etapas & Descrição & Etapas adotadas \\
\hline Identificação do problema & $\begin{array}{l}\text { Examina problemas sociais em sua } \\
\text { complexidade e utiliza abordagens } \\
\text { longitudinais e com múltiplas perspectivas. }\end{array}$ & $\begin{array}{l}\text { Decisão de estudar PcD e o consumo de serviços } \\
\text { básicos por cerca de um ano. }\end{array}$ \\
\hline Grupo de pesquisadores & $\begin{array}{l}\text { Grandes equipes multidisciplinares } \\
\text { multiculturais. }\end{array}$ & $\begin{array}{l}\text { Desenvolvimento em parceria com pedagogos, } \\
\text { psicólogos, assistentes sociais e demais } \\
\text { profissionais da ONG Lar. }\end{array}$ \\
\hline $\begin{array}{l}\text { Definição dos sujeitos de } \\
\text { pesquisa }\end{array}$ & $\begin{array}{l}\text { Amostragem flexível e criativa, equilibrando } \\
\text { rigor e relevância. }\end{array}$ & $\begin{array}{l}\text { Seleção de alunos com deficiência visual, os seus } \\
\text { pais e profissionais da área para condução de } \\
\text { entrevistas. }\end{array}$ \\
\hline $\begin{array}{l}\text { Técnicas de coleta de } \\
\text { dados }\end{array}$ & $\begin{array}{l}\text { Adoção de um conjunto amplo de técnicas } \\
\text { de coleta de dados, buscando maior } \\
\text { inovação nos métodos utilizados. }\end{array}$ & $\begin{array}{l}\text { Adoção de entrevistas narrativas e em } \\
\text { profundidade, além de observações } \\
\text { participantes. }\end{array}$ \\
\hline Aplicação dos resultados & $\begin{array}{l}\text { Análise colaborativa entre pesquisadores e } \\
\text { participantes em prol da comunidade. } \\
\text { Etapa essencial numa pesquisa } \\
\text { transformativa bem planejada. }\end{array}$ & $\begin{array}{l}\text { Os resultados foram transmitidos e o feedback } \\
\text { foi dado pela comunidade escolar } \\
\text { Apresentações foram feitas aos professores, } \\
\text { familiares e membros de ONGs. }\end{array}$ \\
\hline Disseminação da Pesquisa & $\begin{array}{l}\text { Divulgar os resultados da pesquisa em uma } \\
\text { ampla gama de veículos de comunicação } \\
\text { utilizados pelos consumidores. }\end{array}$ & $\begin{array}{l}\text { Buscou-se a divulgação em mídias impressas, } \\
\text { mas não houve interesse para publicação. }\end{array}$ \\
\hline
\end{tabular}

Fonte: Elaborado pelos autores (2017).

Além do processo de pesquisa destacado, outra contribuição transformativa desta investigação está relacionada aos resultados práticos gerados a partir das conclusões da pesquisa. Além das apresentações que foram realizadas, deve ser ressaltado que há 18 organizações da sociedade civil que atuam no atendimento e defesa dos direitos da PcD em João Pessoa e que os principais resultados desta pesquisa foram repassados para os responsáveis dessas organizações e apresentados para colaboradores e usuários da ONG Lar.

As contribuições gerenciais deste estudo são voltadas para escolas que atendem alunos no ensino fundamental. O primeiro passo a ser seguido para a prestação de serviços adequados às crianças cegas e com baixa visão é iniciar o diálogo com os próprios alunos e com os seus responsáveis, como já foi constado em estudos recentes (FARIA, 2015; YU et al., 2015; COELHO; ORSINI; ABREU, 2016). As adaptações necessárias para o desenvolvimento dos alunos, em muitos casos, não dependem de grandes investimentos financeiros, mas da sensibilidade de professores e gestores escolares em prol da inclusão. Os resultados da pesquisa apontam que a adaptação de brinquedos, o diálogo com alunos videntes e seus pais e a aproximação com ONGs são iniciativas que podem ser adotadas pelos representantes da escola, e que não envolvem elevada contrapartida financeira.

Por fim, ressalta-se que diversas pesquisas podem ser desenvolvidas à luz da abordagem transformativa, uma vez que há diversas temáticas socialmente relevantes a serem exploradas e grupos de consumidores que vivenciam situações de vulnerabilidade, como intercambistas, negros, índios e idosos. Outros tipos de deficiência podem ser estudados por pesquisadores de marketing, já que há poucas investigações sobre o assunto e nenhuma sobre o comportamento de consumo de deficientes auditivos - uma relevante lacuna de pesquisa. 


\section{REFERÊNCIAS}

ACR. ASSOCIATION FOR CONSUMER RESEARCH. Transformative Consumer Research. Disponível em: <http://www.acrwebsite.org/web/tcr/transformative-consumer-research. aspx>. Acesso em: 11 jan. 2017.

ADKINS, N.; JAE, H. Marketplace vulnerability of limited English proficient consumers: opportunities to increase knowledge in Macromarketing. Journal of Macromarketing, v. 30, n. 1, p. 93-104, 2010.

AMARO, L. et al. Em que posso ajudar? O varejo e os portadores de deficiência visual. Negócios e Talentos, v. 5, 2008.

ANGROSINO, M. Etnografia e observação participante. In: FLICK, U. (Org.). Coleção pesquisa qualitativa. Porto Alegre: Artmed, 2009.

BAKER, S. Consumer normalcy: understanding the value of shopping through narratives of consumers with visual impairments. Journal of Retailing, v. 82, p. 37-50, 2006.

BAKER, S.; GENTRY, J.; RITTENBURG, T. Building understanding of the domain of consumer vulnerability. Journal of Macromarketing, v. 25, n. 2, p.1-12, 2005.

BAKER, S.; MASON, M. Toward a process theory of consumer vulnerability and resilience: illuminating its transformative potential. In: MICK, D. et al. (eds.). Transformative Consumer Research for personal and collective well being: reviews and frontiers. NY: Routledge, 2012.

BAKER, S.; STEPHENS, D.; HILL, R. Marketplace experiences of consumers with visual impairments: beyond the Americans with Disabilities Act. Journal of Public Policy \& Marketing, v. 20, n. 2, 2001.

BARNARD, J. Consumer rights of the elderly as vulnerable consumers in South Africa: some comparative aspects of the Consumer Protection Act 68 of 2008. International Journal of Consumer Studies, v. 39, n. 3, p. 223-229, 2015.

BARNES, C.; MERCER, G. Disability. Key Concepts (Polity Press), 2003.

BENJAMIM, A.; BESSA, L.; MARQUES, C. Manual de Direito do Consumidor. São Paulo: Revista dos Tribunais, 2007.

BRASIL. Ministério da Educação. Secretaria de Educação à Distância. Deficiência Visual. Brasília: MEC, 2000.

. Lei $n^{\circ}$ 13.146, de 6 de julho de 2015. Institui a Lei Brasileira de Inclusão da Pessoa com Deficiência. Disponível em: <http://www.planalto.gov.br/ccivil_03/_Ato20152018/2015/Lei/L13146.htm>. Acesso em: 10 jul. 2016.

BRENKERT, G. Marketing and the vulnerable. Business Ethics Quarterly, Special Issue, n. 1, p. 7-20, 1998.

CHILDERS, T.; KAUFMAN-SCARBOROUGH, C. Expanding opportunities for online shoppers with disabilities. Journal of Business Research, v. 62, n. 5, p. 572-578, 2009. 
CLOUGH, B. Vulnerability and capacity to consent to sex - asking the right questions? Child and Family Law Quarterly, v. 26, n. 4, 2014.

COELHO, P. A Pesquisa Transformativa do Consumidor: reflexões e diretrizes para pesquisadores brasileiros. E\&G Economia e Gestão, v. 15, n. 40, 2015.

COELHO, P.; ABREU, N. As consequências das falhas nos encontros de serviço em shopping centers: um estudo com consumidores deficientes visuais. In: Seminários em Administração, 18., 2015. São Paulo. Anais... São Paulo: USP, 2015.

COELHO, P.; ORSINI, A.; ABREU, N. Os encontros de serviço de deficientes visuais em Instituições de Ensino Superior. Revista Pensamento Contemporâneo em Administração, v. 10, n. 2, p. 65-79, 2016.

COUTINHO, M. Inclusão da pessoa com deficiência visual na educação superior e a construção de suas identidades. Programa de Pós-Graduação em Educação da Universidade Católica Dom Bosco, 2011 (Campo Grande, MS).

CRESWELL, J. Projeto de pesquisa: métodos qualitativo, quantitativo e misto. Porto Alegre: Artmed, 2007.

CROCKETT, D. et al. Conceptualizing a transformative research agenda. Journal of Business Research, v. 66, n. 8, p. 1171-1178, 2013.

DALL'ACQUA, M. Intervenção no ambiente escolar: estimulação visual de uma criança com visão subnormal ou baixa visão. São Paulo: Editora UNESP, 2002.

DAVIS, B.; PECHMANN, C. Introduction to the special issue on transformative consumer research: developing theory to mobilize efforts that improve consumer and societal well-being. Journal of Business Research, v. 66, p. 1168-1170, 2013.

DÍAZ, F. et al. Educação inclusiva, Deficiência e Contexto social: questões contemporâneas. 2009. Disponível em: <https://repositorio.ufba.br/ri/bitstream/ufba/\%20170/1/ Educacao\%20Inclusiva.pdf>. Acesso em: 15 out. 2016.

FARIA, M. A eterna criança e as barreiras do ter: consumo de pessoas com Síndrome de Down e suas famílias. Tese (Doutorado em Administração) - Instituto Coppead de Administração da Universidade Federal do Rio de Janeiro (COPPEAD/UFRJ), Rio de Janeiro, 2015.

FARIA, M.; MOTTA, P. Pessoas com deficiência visual: barreiras para o turismo de lazer. Revista Turismo em Análise, v. 23, p. 691-717, 2012.

FARIA, M.; SILVA, J.; FERREIRA, J. The visually impaired and consumption in restaurants. International Journal of Contemporary Hospitality Management, v. 24, n. 3, 2012.

FARIA, M.; VERGARA, S.; CARVALHO, L. Pesquisas com foco em Pessoas com Deficiência no campo da Administração: paradigmas e perspectivas epistemológica. Revista Gestão e Planejamento, v. 15, n. 1, p. 21-39, 2014.

FERNANDES, F. Política de ampliação do ensino fundamental para nove anos - Pela inclusão das crianças de seis anos de idade na educação obrigatória. 2006. Disponível em: $<$ http://portal.mec.gov.br/seb/arquivos/pdf/Ensfund/chagas_ensfundnovanos.pdf $>$. Acesso em: 10 nov. 2015. 
FUNDAÇÃO DORINA NOWILL. Relatório Anual de Atividades, 2012. Disponível em: $<$ http://www.fundacaodorina.org.br/uploads/relatorios-anuais/relatorio_anual_2012.doc>. Acesso em: 04 jan. 2016.

GORNI, D. Ensino fundamental de nove anos: estamos preparados para implantá-lo? Ensaio: Avaliação das Políticas Públicas Educacionais, v. 15, n. 54, p.67-80, 2007.

IBGE. Censo Demográfico 2010. Disponível em: <http://www.ibge.gov.br/home/presidencia/noticias/noticia_impressao.php?id_noticia=2170 > . Acesso em: 20 jan. 2017.

JOVCHELOVICH, S.; BAUER M. Entrevista Narrativa. In: BAUER, M.W., GASKELL, G. Pesquisa qualitativa com texto, imagem e som: um manual prático. Petrópolis: Vozes; 2002.

KAUFMAN-SCARBOROUGH, C.; CHILDERS, T. Understanding markets as online public places: insights from consumers with visual impairments. Journal of Public Policy \& Marketing, v. 28, n. 1, p. 16-28, 2009.

KOTLER, P.; LEVY, S. Broadening the concept of marketing. Journal of Marketing, v. 33, p. 10-15, 1969.

LEITE, M.; SILVA, G. R. Inclusão da pessoa com deficiência visual nas instituições de educação superior de Belo Horizonte. In: ENANPAD, 30., 2006, Salvador. Anais... Salvador: ANPAD, 2006.

MAGNANI, J. Etnografia como prática e experiência. Horizontes Antropológicos, Porto Alegre, v. 15, n. 32, p. 129-156, 2009.

MANTOAN, M. Inclusão escolar: O que é? Por quê? Como fazer? São Paulo: Moderna, 2003.

MICK, D. et al. Origins, qualities, and envisionments of Transformative Consumer Research. In: MICK, D. et al. (Eds.) Transformative Consumer Research for personal and collective well being: reviews and frontiers. NY: Routledge, 2012.

MICK, D. Meaning and mattering through transformative consumer research. Presidential Address before the Association for Consumer Research. Advances in Consumer Research, v. 33, p. 1-4, 2006.

MORGAN, F.; SCHULER, D.; STOLTMAN, J. A framework for examining the legal status of vulnerable consumers. Journal of Public Policy and Marketing, v. 14, n. 2, p. 267-277, 1995.

MUYLAERT, C. et al. Entrevistas narrativas: um importante recurso em pesquisa qualitativa. Revista da Escola de Enfermagem da USP, Brasil, v. 48, p. 184-189, 2014.

OLIVEIRA, R. Da universalização do ensino fundamental ao desafio da qualidade: uma análise histórica. Educação \& Sociedade, v. 28, n. 100. p. 661- 690, 2007.

PASCHOAL, C.; GOMES, M.; BRASIL, P. Instituto Benjamin Constant em prosa, verso e sonhos. Rio de Janeiro: Instituto Benjamin Constant, 2014.

PETKUS, E. Incorporating Transformative Consumer Research into the consumer behavior course experience. Journal of Marketing Education, v. 32, n. 3, p. 292-299, 2010. 
PINHEIRO, M.; PENA DA SILVA, E.; RODRIGUES, L. O ir e vir dos deficientes visuais: barreiras arquitetônicas e acadêmicas na UFMT. Inclusão Social, v. 3, n. 1, p. 48-65, 2008.

PINTO, A. A Inversão do ônus da prova nas relações consumeristas. Revista de Direito do Tribunal de Justiça do Estado do Rio de Janeiro, v. 1, n. 71, p.13-20, 2007.

PINTO, M.; FREITAS, R. O que os olhos não veem o coração não sente? Investigando experiências de compra por deficientes visuais no varejo de roupas. REGE, v. 20, n. 3, p. 387-405, 2013.

PINTO, M. R. et al. Transformative Consumer Research (TCR): Reflexões, Diretrizes e uma Análise do Campo no Brasil. Revista Interdisciplinar de Marketing - RIMAR, v. 6, n. 2, p. 54-66, 2016.

RAMOS, S. Desafios da convivência no espaço educacional inclusivo: um estudo de caso etnográfico sobre a deficiência visual. Dissertação (Mestrado em Educação). Programa de Pós-Graduação em Educação da Universidade Federal do Piauí, Teresina, 2007.

RAPP, J. M.; HILL, R. P. “Lordy, Lordy, Look Who's 40!” The Journal of Consumer Research Reaches a Milestone. Journal of Consumer Research, v. 42, n. 1, p. 19-29, 2015.

SANTOS, L.; VIEIRA, L. Agora seu filho entra mais cedo na escola: a criança de seis anos no ensino fundamental em Minas Gerais. Educação \& Sociedade, v. 27, n. 96, p. 775-796, 2006.

SHULTZ II, C. J.; HOLBROOK, M. B. The paradoxical relationships between Marketing and vulnerability. Journal of Public Policy \& Marketing, v. 28, n.1, p. 124-127, 2009.

SMEHA, L.; SEMINOTTO, N. Educação inclusiva: perspectivas da diferença no grupo de alunos. Revista Educação, v. 33, n.2, p. 305-322, 2008.

TADAJEWSK, M.; HAMILTON, K. Waste, Art, and Social Change: Transformative Consumer Research Outside of the Academy? Journal of Macromarketing, v. 34, n. 1, p. 80-86, 2014.

TURETA, C. Práticas organizativas em escolas de samba: o setor de harmonia na produção do desfile do Vai-Vai. 2011. Tese (Doutorado em Administração de Empresas) - Escola de Administração de Empresas da Fundação Getúlio Vargas (EAESP/FGV), São Paulo, 2011.

VELUDO-DE-OLIVEIRA, T.; IKEDA, A. Valor em serviços educacionais. RAE electron., São Paulo, v. 5, n. 2, 2006.

. Servqual em instituições educacionais: um estudo comparativo. Alcance (UNIVALI), v. 14, p. 189-206, 2007.

YU, H.; TULLIO-POW, S.; AKHTAR, A. Retail design and the visually impaired: A needs assessment. Journal of Retailing and Consumer Services, v. 24, p. 121-129, 2015.

Data de submissão: 24/08/2016.

Data de aprovação: 24/05/2017. 